\title{
The Effectiveness of Dialectical Behavior Therapy on Reducing Symptoms of Borderline Personality Disorder: Case Study
}

\author{
Gamal Abdelhamid Gado
}

\begin{abstract}
This research aimed to examine individual dialectical behavior therapy with a female, she was 21 years old, suffered from borderline personality disorder symptoms. The assessment for the client depended on three tools, the first was clinical interviews, the second was indirect observation, and the third was scale of borderline personality disorder. The more reasons of borderline personality disorders to the client were frequent family problems, case of broken homes, and traumas which happen to the client like sexual harassment. The therapeutic program consisted of 18 sessions, it has been constructed on the principles, strategies, and techniques to Marsha Linehan's practice guide for dialectical behavior therapy, therapeutic program was effectiveness in reducing symptoms of borderline personality disorder.
\end{abstract}

Index Terms-Dialectical behavior therapy, borderline personality disorder, case study.

\section{THEORITICAL AND RESEARCH BASIS}

Borderline personality disorder is the most frequent and the most severe of all personality disorders in clinical practice [1], it's a serious mental disorder with a characteristic pervasive pattern of instability in affect regulation, impulse control, interpersonal relationships, and self-image [2]. It's characterized by severe psychological impairment and high mortality rate due to suicide - up to $10 \%$ of patients commit suicide, a rate almost 50 times higher than in the general population [3], [4], Links have been suggested between borderline personality disorder and criminal risk [5]. It affects about $1-2 \%$ of the general population, up to $10 \%$ of psychiatric outpatients, and $20 \%$ of inpatients [6]. Finding of studies showed that the disorder was more common in women than in men, and in girls than boys, about $70 \%$ for men and $30 \%$ for women [7], the prevalence of borderline personality disorder was $11 \%$ at age $9-19$ years, and $7.8 \%$ at 11 - 21 years [8].

The cause of borderline personality disorder is complex with several factors, which interact in various ways with each other, genetic factors and adverse childhood experiences might cause emotional dysregulation and impulsivity leading to dysfunctional behaviors and psychological conflicts and deficits [9], current theories indicate that the etiology of borderline personality disorder may be related to genetic or neurobiological factors, family environment (including

Manuscript received July 18, 2014; revised September 25, 2014.

Gamal Abdelhamid Gado is with the Aswan Higher Institute of Social Work, Egypt, and with Department of Psychology, Faculty of Education, Qassim University, KSA (e-mail: drgamalgado@yahoo.com). attachment, parental pathology and childhood abuse), and social factors [10], childhood sexual abuse has been particularly associated with diagnosis of borderline personality disorder [11], research in this field has focused mainly on the role of intrafamilial trauma, such as physical and sexual abuse, studies also have investigated the role of other traumatic conditions, such as intrafamilial violence, neglect, early separation and losses as possible risk factors in the development of borderline personality disorder [12], [13]. The American psychiatric Association [14] showed 9 criteria for borderline personality disorder and the individuals with it have 5 or more of these criteria which are: frantic efforts to avoid real or imagined abandonment, a pattern of unstable and intense interpersonal relationships characterized by alternating between extremes of idealization and devaluation, identity disturbance, impulsivity in at least two areas that are potentially self - damaging, recurrent suicidal or self-mutilating behavior, affective instability due to a marked reactivity of mood, chronic feelings of emptiness, inappropriate intense anger or difficulty controlling anger, and stress-related paranoid ideation or severe dissociative symptoms.

The American psychiatric Association [4] recommended of cognitive behavior therapy especially dialectical behavior therapy as psychotherapy for borderline personality disorder, dialectical behavioral therapy is a cognitive behavioral approach to treating borderline personality disorder, despite an extensive literature on the psychotherapeutic treatment of people with borderline personality disorder, few approaches are supported by research [15]. Dialectical behavior therapy was developed by Marsha Linehan [16], [17], a clinical psychologist, to address the treatment needs of individuals with a diagnosis of borderline personality disorder and a history of parasuicidal behaviors [18]. Dialectical behavior therapy is an ongoing focus on behavioral change is balanced with acceptance, compassion and validation of the client [15]. Dialectical behavior therapy is a four stages treatment, in stage 1 the primary focus is on stabilizing the patient and achieving behavioral control [18], the target behaviors are: (a) decreasing life threatening suicidal behaviors, (b) decreasing therapy interfering behaviors, (c) decreasing quality of life interfering behaviors, (d) increasing behavioral skills [19], [20], in stage 2 the focus is on treating problems related to the past trauma, in stage 3 the emphasis is on the development of self-esteem and the effective management of problems of daily living, stage 4 sees the individual as seeking to develop the capacity for optimum experiencing [20], [21].

More studies examined the effectiveness of dialectical behavior therapy on reducing borderline personality disorder 
symptoms like : Shearin \& Linehan [22]; Bohus et al. [23]; Koons et al. [24]; Stenhouse \& Kessel [25]; Esbensen \& Benson [26]; Bohus et al. [27], Kroger et al. [28]; Nee \& Forman [29]; Stepp et al. [30]; Goodman et al. [31] ; Kliem et al. [20] . Most studies relied on criteria of borderline personality disorder in DSM-IV for diagnosis the disorder, and most studies relied on principals and strategies of dialectical behavior therapy to Marsha Linehan [16], [17], and the guide which produced by the American Psychiatry Association [4].

\section{CASE PRESENTATION}

Ms. Nahed (not her real name), 21 years old, a university student, her family consisted of eight members (father, mother, four daughters and two sons), she is the third between her brothers and sisters. She required treatment assistance after several attempts of suicide, and many problems of poor compatibility with peers and members of her family, and after a sense of emptiness and constantly thinking about death. She was sad and dissatisfied with all aspects of her life and nothing was good enough.

According to Diagnostic and Statistical Manual of Mental Disorders DSM-IV [14], she has been diagnosed with borderline personality disorder. It has been offering 18 treatment sessions to her for purity over 10 months, one session every week, adopted therapeutic program on the basics and techniques of Dialectical behavioral therapy, and preceded by several clinical interviews to hearing the client complaint and notes from her friends, including for the purpose of access to diagnosis to the situation, as has been application of a measure of borderline personality disorder.

\section{CASE HiSTORY}

Nahed described her father as a strong, bossy and stubborn, he often located outside the home because of the nature of his work, which made him wake up early on a daily basis, although it is a lot, staying up at around $3 \mathrm{Am}$ and spend this time in a nightclub. She described her feelings toward her father as hate and contempt (although he always shows his feelings of love and compassion to her) because of his behavior and that he was the cause of the loss of a great fortune he inherited from her grandfather and spent on pleasures. Her mother was smaller than the father at about 3 years, a housewife, relationship between mother and father was tepid, there was no love or understanding between them, always they were in quarrel and problems between them, the mother was suffering from a drop in blood pressure and diabetes, although the mother looks affectionate and friendly with Nahed but the purity of their relationship is not strong enough, She has received the support and cordiality from the others but not from her family. Nahed was very closely with her sister which is older than her, her sister has gone to live with her husband in his town since she married. Nahed was born in the family house, she lived the period of her childhood in this house, her grandfather was very affectionate with her. She liked study days, very simply because they were graduating from the house which she hated, and she has gone daily to her college whether there is a lectures or not. She had been admitted to hospital by two of her friends and socialist after a suicide attempt, she had a calming pills frequently without a physician consultation.

She has seen in her dreams frequently one of her professors, she has seen him sitting in his office and advices her gently, she hoped if this professor was her father. Nahed was sexually harassed several times when she was at the beginning of adolescence by one of her male relatives, he was married of her aunt and almost age-old like her father.

\section{COMPlaints AS THE CliENT SAID}

In the last days, she became hating prayers and holly Quran and felt many physical pains. She tried to suicide several times, she had a severe loss of appetite, Nahed was so afraid of losing her friends, she feels that they despise her because of her behaviors and mistakes, she feels hating her father and suffering from screaming and anger crisis. She cut her hair completely to provoke her father, she thought more than time to burn the family home or killing all of them, she admires with old and married men.

\section{TOOLS}

The current study has been relying on the following tools:

1) Clinical interviews with the client.

2) Indirect observation.

3) Scale of borderline personality disorder by Musalam [32], this scale has been constructed in 9 subscales, each one contains 3 items, all subscales and its items were derived from borderline personality disorder criteria in diagnostic and statistical manual of mental disorders, DSM-IV [14], the person who diagnosed with borderline personality disorder needs to provide five Criteria of the nine given in DSM-IV. The client responds to the scale items by choosing from 5 categories of responses ranging in strength, the less score on the scale is 27 and the high score is 135 , Musalam [32] has been ensured from scale validity and reliability $(r=0.87)$, Musalam considered the score of 75 on the borderline personality disorder scale is cut point for diagnosis with the disorder.

\section{ASSESSMENT}

Assessment has been essentially depended on criteria of borderline personality disorder in DSM-IV by American Psychiatric Association [14], the open clinical interviews and observations reports by her friends and socialist, study of the client case history, and the complaints as the client said, all of that ensured she has been suffering from the following:

1) Emotional instability: case of emotional disturbance and tension, reactivity of mood, chronic feeling of vacuum, continuous of inappropriate anger and screaming innings, and difficulty in expression or controlling this anger.

2) Interpersonal difficulties, chaos and Lack of concentration in personal and emotional relationships.

3) Behavioral problems, several suicide attempts, taking sedative pills, self-injuries and damaging behaviors. 
4) Lack of self-regulation, and continuous need to others.

5) Moreover, she scored on the borderline personality disorder scale 94 degree (the total score was 135).

The main reasons for these symptoms were:

1) The absence of modeling role specially from her father.

2) Frequent problems and family conflicts especially between father and mother.

3) Emotional deprivation and lack of satisfying psychological needs, such as the needs of love and appreciation, belonging and security.

4) Psychological trauma as a result of sexual harassment .

5) There was no psychological support from her family, and wrong approaches in social upbringing like discrimination, it makes her be jealousy from her big sister.

\section{PSYCHOTHERAPY INTERVENTION AND ASSESSMENT OF PROGRESS}

Individual dialectical behavior therapy was provided for Nahed, dialectical behavior therapy was developed initially for the treatment of chronically suicidal or self-injurious patients [16], [17], and it's a cognitive behavioral approach to treating borderline personality disorder [15]. The primary dialectic upon which the treatment rests in the balance on synthesis of acceptance of the client as he is currently using validation strategies with the attempt to get the client to change using behavior therapy strategies [24]. In this study, the treatment sessions period was 10 months, it was presented 18 sessions in two time stages, in the first stage the client got one session weekly and in the second stage she got one session for two weeks, that was because of reducing the client dependence and promote independence.

The treatment program has been constructed of three basic elements in the dialectical behavior therapy, these elements are dialectical, validation, and Mindfulness, it has been constructed from the practice Guide to Linehan [17].

Dialectical means that 2 ideas can both be true at the same time. The client learned dialectical thinking and behaviors from some practices like practice of "do and don't", in "do" practice the client learns to move away from " either - or "thinking to" both - and " thinking, avoid extreme words like always never, you make me, for example Instead of saying: everyone always acts with me unfairly, say: sometimes some people act with me fairly and some act with me unfairly. But in "don't" practice the client learns to don't assume that she knows what others are thinking, check it out by asking them "what did you mean when said.....?", and also the client learns to don't expect others to know what she are thinking, be clear by saying "what I'm trying to say is...?". Some dialectics homework sheets were given [17].

Validation means telling someone that what they feel, think, believe, and experience is real logical understandable and self-validation is when you are able to quietly reassure yourself that what you feel inside is real, is important and makes sense. In dialectical behavioral therapy clients learn to validate others because it helps their relationships go better, and it calms intense situation so that we can problem solve, and also they learn self - validate. To help the client getting validation, the treatment program depended on 5 validation strategies which used in Linehan training guide [17], the first strategy was "focus on the inherent worth of the person", the second was "observe - listen carefully to what is said with words, expression, and body intently listen, be one - mindful in the moment", the third was "describe - non judgmentally state the facts of the situation", the fourth was "state the unstated, note the presence of feelings, beliefs, ... etc. that haven't been voiced", and the fifth was "find what is true / valid about the experience and note this", for these five strategies, the client has been practiced some validation practices.

Mindfulness means taking control of your attention and thoughts, for mindfulness the client may has some skills like observation, description, and participation, the client was given practices for observing and describing thoughts. Also she was practicing on linehan's model of "D-E-R-M-A-N" [22], to improve interpersonal effectiveness skills.

The course of treatment was in 21 months (with the follow up period), the first follow - up was after 6 months, and the second was after 1 year from the last treatment session with the client, there were four measures (pretest, posttest, first follow up, \& second follow up) on the borderline personality disorder scale, which are in the following Table I:

TABLE I: OUTCOME MEASURE ACROSS THE COURSE OF TREATMENT

\begin{tabular}{lllllllllll}
$\begin{array}{l}\text { Subscales } \\
\text { Test }\end{array}$ & F1 & F2 & F3 & F4 & F5 & F6 & F7 & F8 & F9 Total \\
\hline Pretest & 9 & 12 & 11 & 10 & 11 & 13 & 10 & 10 & 8 & 94 \\
Posttest & 4 & 7 & 6 & 5 & 6 & 7 & 5 & 6 & 7 & 53 \\
6 months- & & & & & & & & & & \\
follow up & 5 & 6 & 6 & 6 & 5 & 7 & 4 & 6 & 7 & 52 \\
1 year- & & & & & & & & & & \\
follow up & 4 & 6 & 7 & 5 & 6 & 7 & 5 & 6 & 7 & 53 \\
\hline \hline
\end{tabular}

F1: Desertion avoid behaviors, F2: Interpersonal relationships, F3: Identity disorder, F4: Impulsivity, F5: Emotional instability, F6: Suicide and self -harm behaviors, F7: Emptiness feelings, F8: Difficulty controlling anger, F9: Paranoia symptoms.

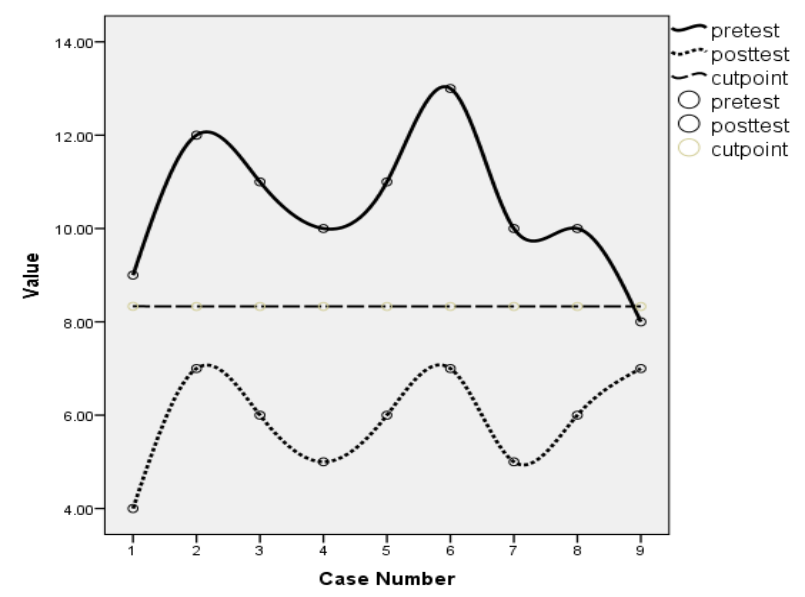

Fig. 1. Chart showing for pretest, posttest and cut point for the client on borderline personality disorder scale. 


\section{DISSCUSION}

The client (Nahed) has great difficulty in accepting herself and others, like all clients with borderline personality disorder [29], dialectical behavioral therapy leads to development of acceptance skills. It consists of four primary treatment stages, most of researches in dialectical behavior therapy focus in stage 1 , it's usually designed to get the client's behaviors under control because of the clients are suicidal [33]. In stage 2, the use of dialectical behavior therapy focuses on helping clients to restore a sense of hopefulness and begin to manage emotional and behavioral problems associated with daily living, also dialectical behavior therapy in stage 2 focus on enhancing emotional regulation and improving self-management, in stage 3 (adaptation stage), the therapist and the client work to enhance abilities to see the whole as well as its parts, therapeutic learning focuses on ways to cope with the dialectical conflicts implicit in competencies and deficits, challenges and victories [34], in stage 4, the treatment focuses on the desire to feel completeness and joy [33]. The current dialectical behavior therapy program constructed of main therapeutic strategies by Linehan [16], [17], dialectic, validation, and mindfulness in parallel with the obvious four stages for dialectical behavior therapy. For these strategies, the therapeutic program depended on some of available techniques such as metaphor using, paradoxes using, role play of devil's defense, dialectical assessment, extension, do and don't, meditation, focusing, encouragement, relaxation practices, and training on skills of problem solving, validation and mindfulness techniques.

Examination of pretest and posttest revealed that the client (Nahed) enrolled in the dialectical behavioral therapy program experienced a reduction in borderline personality disorder symptoms as measured by Musalam [32], test of borderline personality disorder, there was a reduction in the total score and several subscales including desertion avoid behaviors, interpersonal relationships, identity disorder, impulsivity, emotional instability, suicide and self -harm behaviors, emptiness feelings, difficulty controlling anger, and paranoia symptoms. It was also found that skills utilization increased over time after treatment sessions, this finding could be interpreted as the client has been strengthening her skills use, and she has been generalizing skills taught in the therapeutic program to new situations over follow period.

At the last phone with Nahed, she told me that she found work in special mental health hospital, despite of the salary was too less, but she got the job and felt happiness with it. She engaged with her colleague in the same hospital (he was youth man not old or married), and they will be married. She was feeling happiness, and shyness of all her obvious behaviors and mistakes. She had a new view of life, always she has something to do, there's no feeling with emptiness.

\section{RECOMMENDATION}

The researcher recommends with the following:

1) Moderation in the methods of socialization and non-discrimination between sons in the same family.
2) Availability of role models in the family, especially from parents.

3) Examine the effectiveness of both individual and group dialectical behavior therapy on reducing borderline personality disorder and other personality disorders.

Study the reasons and risks of borderline personality disorder in Arabic societies.

\section{REFERENCES}

[1] R. Kenz, "Gestalt psychotherapy in the outpatient treatment of borderline personality disorder: a case report," AFR Psychiatry, vol. 16, pp. 52-54, 2013.

[2] K. Lieb, "Borderline personality disorder," Lancet Journal, vol. 364, pp. 453-461, 2004.

[3] A. Skodol, J. Ganderson, and T. McGlashan, "Functional impairment in patients with schizotypal, borderline, avoidant, or obsessive-compulsive personality disorder," Am J Psychiatry, vol. 159, pp. 276-83, 2002.

[4] American Psychiatric Association, Diagnostic and Statistical Manual of Mental Disorders, DSM-IV, 4th Ed. , Washington : The American Psychiatric Association Press , 1994, pp. 650-654.

[5] S. Farman and C. Nee, "Dialectical behavior therapy as a treatment for borderline personality disorder in prisons: three illustrative case studies," The Journal of Forensic Psychiatry and Psychology, vol. 18, no. 2, pp. 160-180, 2007

[6] S. Torgerson, E. Kringlen, and V. Cramer, "The prevalence of personality disorders in a community sample," Arch Gen Psychiatry, vol. 58, pp. 590-596, 2001.

[7] T. Widiger and M. Weissman, "Epidemiology of borderline personality disorder," Hosp Comm Psychiatry, vol. 42, pp. 1015-1036, 1991.

[8] L. Klaus, M. Zanarini, C. Schmahl, M. Linehan, and M. Bohus. (2014). Borderline Personality Disorder, Psychiatric Disorders. Proquest Digital Information, [Online]. 6(7). Available: http://search.proquest.com/docview/199002969?accountied=30906

[9] A. Skodol, L. Siever, W. Livesley, J. Gunderson, B. Pfohl, T. Wideger, W. Torrey, and K. Koerner, "The borderline diagnosis II: biology, genetics, and clinical course," Biol Psychiatry, vol. 51, pp. 951- 994, 2002 .

[10] N. Nehls, "Borderline personality disorder: gender stereotypes, stigma, and limited system of care," Issues in Mental Health Nursing, vol. 19, pp. 97-112, 1998.

[11] S. Brown, "EMDR in the treatment of borderline personality disorder," Clinical Case Studies, vol. 5, no. 5, pp. 403-420, 2006.

[12] G. Liotti and P. Pasquini, "Predictive factors for borderline personality disorder: patients' early traumatic experiences and losses suffered by the attachment figure," Acta Psychiatr Scand, vol. 102, pp. 282-289, 2000.

[13] J. Oldham, A. Kodol, P. Dallaher, and M. Kroll, "Relationship of borderline symptoms to histories of abuse and neglect: a pilot study," Psychiatr Q, vol. 67, pp. 287-295, 1996.

[14] American Psychiatric Association, "Practice guideline for the treatment of patients with borderline personality disorder-introduction," Am J. Psychiatry, vol. 158, pp. 28-52, 2001.

[15] C. Swenson, "Implementing dialectical behavior therapy," Psychiatric Services, vol. 53, no. 2, pp. 171-178, 2002.

[16] M. Linehan, Cognitive Behavioral Treatment of Borderline Personality Disorder, New York: The Guilford Press, 1993.

[17] M. Linehan, Skills Training Manual for Treating Borderline Personality Disorder, New York: Guilford Press, 1993.

[18] R. Blennerhassett and J. O'raghallaigh, "Dialectical behavior therapy in the treatment of borderline personality disorder," British Journal of Psychiatry, vol. 186, pp. 278-280. 2005.

[19] L. Dimeff and M. Linehan, "Dialectical behavior therapy in a nutshell," The California Psychologist, vol. 34, pp. 10-13, 2001.

[20] S. Kliem, C. Kroger, and J. Kosfelder, "Dialectical behavior therapy for borderline personality disorder: a meta-analysis using mixed-effects modeling," Journal of Consulting and Clinical Psychology, vol. 78, no. 6, pp. 936-951, 2010.

[21] D. Black, N. Blum, P. Pfohl, and N. Hale, "Suicidal behavior in borderline personality disorder: prevalence, risk factors, prediction, and prevention," Journal of Personality Disorders, vol. 18, pp. 226-239, 2004.

[22] E. Shearin and M. Linehan, "Dialectical behavior therapy for borderline personality disorder: theoretical and empirical foundation," Acta Psychiatr Scand, vol. 379, pp. 61-68, 1994. 
[23] M. Bohus, B. Haaf, C. Stiglmayr, U. Pohl, R. Bohme, and M. Linehan, "Evaluation of inpatient dialectical-behavioral therapy for borderline personality disorder: a prospective study," Behavior Research and Therapy, vol. 38 , pp. 875-887, 2000.

[24] C. Koons, C. Robins, J. Tweed, T. Lynch, A. Gonzalez, J. Morse, G. Bishop, M. Butterfield, and L. Bastian, "Efficacy of dialectical behavior therapy in women veterans with borderline personality disorder," Behavior Therapy, vol. 32, pp. 371-390, 2001.

[25] L. Stenhouse and K. Kessel, "Cognitive therapy and dialectical behavior therapy: an integrative approach to the conceptualization of borderline personality disorder," New Zealand Journal of Psychology, vol. 31, no. 2, pp. 87-92, 2002.

[26] A. Esbensen and B. Benson, "Integrating behavioral, psychological and pharmacological treatment: a case study of an individual with borderline personality disorder and mental retardation," Mental Health Aspects of Developmental Disabilities, vol. 6, no. 3, pp. 68-76, 2003.

[27] M. Bohus, B. Haaf, T. Simms, M. Limberger, C. Schmahl, C. Unikel, and M. Linehan, "Effectiveness of inpatient dialectical behavioral therapy for borderline personality disorder: a controlled trial," Behavior Research and Therapy, vol. 42, pp. 487-499, 2004.

[28] C. Kroger, U. Schweiger, V. Sipos, R. Arnold, K. Kahl, T. Schunert, S. Rudolf, and H. Reinecker, "Effectiveness of dialectical behavior therapy for borderline personality disorder in an inpatient setting," Behavior Research and Therapy, vol. 44, pp. 1211-1217, 2006.

[29] C. Nee and S. Farman, "Dialectical behavior therapy as a treatment for borderline personality disorder in prisons: three illustrative case studies," The Journal of Forensic Psychiatry \& Psychology, vol. 18, no. 2, pp. 160-180, 2007.

[30] S. Stepp, A. Epler, S. Jahng, and T. Trull, "The effect of dialectical behavior therapy skills use on borderline personality features," Journal of Personality Disorders, vol. 22, no. 6, pp. 549-563, 2008.
[31] M. Goodman, E. Hazlett, A. New, H. Koenigsberg, and L. Siever, "Quieting the affective storm of borderline personality disorder," $\mathrm{Am} J$. Psychiatry, vol. 166, no. 5, pp. 522-528, 2009.

[32] Y. Musalam, "Self-harm and its relation to borderline personality disorder and depression in a sample of inmates at a correctional and rehabilitation center," MD, Faculty of Higher Studies, University of Jordan, 2007.

[33] C. Freeman and M. Power, Handbook of Evidence - Based Psychotherapies: A Guide for Research and Practice, New Jersey: John Wiley \& Sons Ltd. Press, 2007.

[34] S. Parkel and A. Bailey, "Dialectical behavior therapy: application of DBT principles in rehabilitation and treatment processes for individual with spinal cord injuries or diseases," Psychosocial Journal, vol. 18, pp. 136-143, 2005.

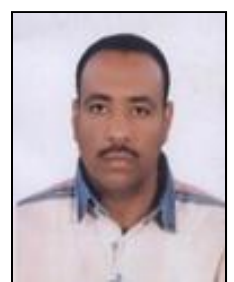

Gamal Abdelhamid Gado was born in Aswan, Egypt on January 4, 1976. He holds a Ph.D. degree in psychology mental hygiene in 2007 from Mental Hygiene Department, Qena Faculty of Education, South Valley University. He holds a master degree in psychology mental hygiene in 2003 from Psychology Department, Aswan Faculty of Education, South Valley University.

$\mathrm{He}$ is an assistant professor at Qassim University, Faculty of Education, Department of Psychology (KSA), and Aswan Higher Institute of Social Work (Egypt). And he's currently interested in psychotherapy and counseling.

Dr. G. Gado is a member of the Egyptian Psychologists Association (EPA). 